\title{
Propellant Charring in Pulsed Plasma Thrusters
}

\author{
Michael Keidar* and Iain D. Boyd ${ }^{\dagger}$ \\ University of Michigan, Ann Arbor, Michigan 48109 \\ Erik L. Antonsen \\ University of Illinois at Urbana-Champaign, Urbana, Illinois 61801 \\ and \\ Frank S. Gulczinski III ${ }^{\S}$ and Gregory G. Spanjers ${ }^{\mathbb{I}}$ \\ U.S. Air Force Research Laboratory, Edwards Air Force Base, California 93524
}

\begin{abstract}
The Teflon ${ }^{\mathrm{TM}}$ ablation in a micro-pulsed plasma thruster is studied with the aim of understanding the charring phenomenon. Microscopic analysis of the charred areas shows that it contains mainly carbon. It is concluded that the carbon char is formed as a result of carbon flux returned from the plasma. A simplified model of the current layer near the Teflon surface is developed. The current density and the Teflon surface temperature have peaks near the electrodes that explain preferential ablation of these areas, such as was observed experimentally. Comparison of the temperature field and the ablation rate distribution with photographs of the Teflon surface shows that the area with minimum surface temperature and ablation rate corresponds to the charring area. This finding suggests that the charring may be related to a temperature effect.
\end{abstract}

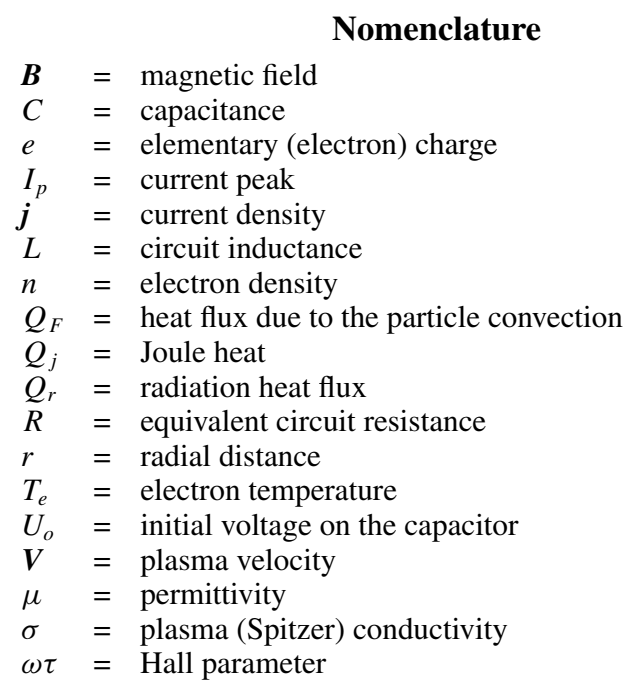

I. Introduction

$\mathbf{P}$ ULSED plasma thrusters (PPTs) have been investigated since the early 1960s and were among the first of various electrical propulsion concepts accepted for space flight, mainly due to their simplicity and high reliability. ${ }^{1}$ However, the PPT has a low efficiency of $10 \%$ (Ref. 2) and therefore several ways of improving it have been suggested. ${ }^{3}$ Currently, PPTs are considered an at-

Received 15 May 2003; revision received 2 April 2004; accepted for publication 27 March 2004. Copyright (C) 2004 by the American Institute of Aeronautics and Astronautics, Inc. All rights reserved. Copies of this paper may be made for personal or internal use, on condition that the copier pay the $\$ 10.00$ per-copy fee to the Copyright Clearance Center, Inc., 222 Rosewood Drive, Danvers, MA 01923; include the code 0748-4658/04 \$10.00 in correspondence with the CCC.

*Research Scientist, Department of Aerospace Engineering; keidar@ engin.umich.edu. Senior Member AIAA.

${ }^{\dagger}$ Professor, Department of Aerospace Engineering. Associate Fellow AIAA.

${ }^{\ddagger}$ Undergraduate Student, Department of Aerospace and Aeronautics. Student Member AIAA.

${ }^{\S}$ Researcher, Electric Propulsion Laboratory, Propulsion Directorate. Member AIAA.

IIProgram Manager, Electric Propulsion Laboratory, Propulsion Directorate; currently Program Manager, Space Vehicles Directorate, Kirtland AFB, NM, 87117. Member AIAA. tractive propulsion option for stationkeeping and drag makeup purposes for mass- and power-limited satellites. ${ }^{4,5}$ An electromagnetic PPT was successfully operated for pitch axis control on the EO1 spacecraft. ${ }^{6,7}$ Recently, a micro-PPT has been designed at the Air Force Research Laboratory (AFRL) for delivery of very small impulses. ${ }^{8,9}$ This is a simplified, miniaturized version of a conventional PPT with a thrust in the $10-\mu \mathrm{N}$ range and energy level of about 1-10 $\mathrm{J}(\sim 1-\mathrm{Hz}$ repetition rate) designed to provide attitude control and stationkeeping for microsatellites.

Complete assessment of the spacecraft integration effects requires characterization of the plasma-plume exhaust of a PPT. Previously we have developed an end-to-end model of the PPT and its plume with application to electrothermal ${ }^{10,11}$ and electromagnetic PPTs. ${ }^{12}$ It became clear that the plasma distribution in the plume field depends heavily on upstream boundary conditions. Therefore the model of plasma generation in these devices becomes a very important aspect of accurate plasma-plume simulation. In the present paper we will focus on a micro-PPT. Inspection of the micro-PPT propellant surface after firing indicated signs of charring and preferential ablation near the electrodes. ${ }^{8,9,13}$ It was identified that char formation is the main failure mechanism in the case of low energyto-thruster-radius ratio. ${ }^{13}$ In this paper we present results of microscopic analyses of the charred areas and propose a mechanism of char formation. To understand this phenomenon, a model of the plasma layer near the Teflon ${ }^{\mathrm{TM}}$ surface is developed. In addition, the solution of the model provides boundary conditions for simulating the plasma plume.

\section{Micro-Pulsed Plasma Thruster}

The AFRL MicroPPT uses a three-electrode configuration. ${ }^{8,9} \mathrm{~A}$ small-diameter rod (center electrode) is encased in a small-diameter annulus of Teflon, which is then encased in a relatively smalldiameter tube, which acts as the intermediate electrode. This construction is then encased in a second, larger-diameter annulus of Teflon, which is then encased in a large-diameter outer electrode. The MicroPPT is fired by a low-energy breakdown between the intermediate and central electrodes. This discharge provides enough seed ionization to make possible a higher-energy conduction breakdown between the intermediate and outer electrodes. The discharge between the intermediate and central electrodes is referred to as the trigger discharge. The discharge between the intermediate and outer electrodes is referred to as the "main discharge." Although a wide range of parameters are tested in various MicroPPT configurations, typically the trigger discharge will consume about 1/50 the energy of 
the main discharge. In this fashion, the MicroPPT has demonstrated the ability to initiate a surface-breakdown discharge across outer propellant diameters as large as $\frac{1}{4}$ in. using a relatively low voltage, below $3000 \mathrm{~V}$, without external trigger. Without the three-electrode configuration, up to $40 \mathrm{kV}$ would be required to initiate the discharge across a $\frac{1}{4}$ in.-diam gap, which would place excessive design requirements on the power-processing unit and on the spacecraft EMI shielding.

In this work, research is performed on two-electrode MicroPPT configurations as shown in Fig. 1. The discharge occurs between an inner cathode rod and an outer anode tube, across a Teflon annulus. Understanding the physical processes in this simplified geometry has proven beneficial in advancing the optimization of the MicroPPT by separating the requirements for the trigger and main discharges. Research ${ }^{13}$ on small-diameter two-electrode designs, generally between 1 and $3 \mathrm{~mm}$, is applicable to the trigger discharge. Research $^{8,9,14}$ on larger-diameter two-electrode designs, typically between 3 and $7 \mathrm{~mm}$, is more applicable to the main discharge.

\section{Microscopic Analyses of the Teflon Surface}

MicroPPT propellant samples with two electrodes and different anode diameters were analyzed. These samples represent a fully charred, a partially charred, and an uncharred Teflon surface. The experiments were conducted under a base pressure of $10^{-6}$ torr. Microscopic analyses were performed on the environmental scanning electron microscope available at the Electron Microbeam Analyses Laboratory at the University of Michigan. X-ray energy-dispersive spectroscopy (XEDS) makes it possible to identify the chemical elements. We present some characteristic images taken from the fully charred sample.

Two different structures are identified in the charred area (shown as Area 1 and Area 2 in Fig. 2). The XEDS results in Fig. 3 show that Area 1 mainly contains carbon and small fractions of fluorine

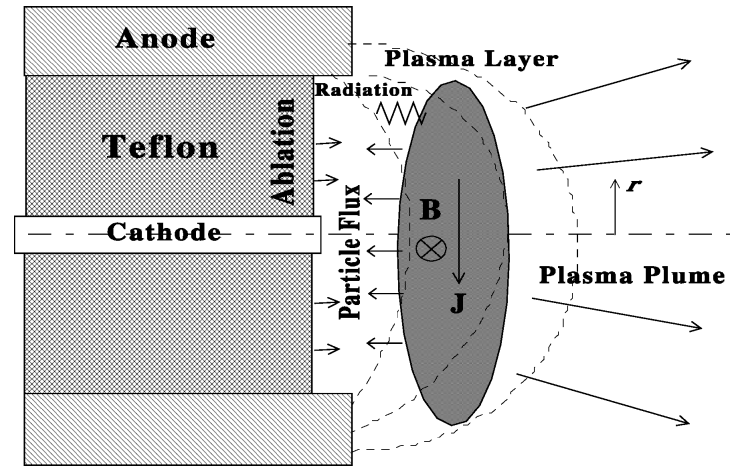

Fig. 1 Schematic of the coaxial micro-PPT electrode configuration.
(F), copper $(\mathrm{Cu})$, silver $(\mathrm{Ag})$, and silicon $(\mathrm{Si})$, whereas the char in Area 2 consists mainly of silicon. Small fractions of $\mathrm{Cu}$ and $\mathrm{Ag}$ are also found. Visual analysis of the interface between Areas 1 and 2, as shown in Fig. 2, suggests that the same Si-dominated structure (as in the image; Fig. 3b) may lie under the carbon charring. In order to verify this we removed the carbon layer with stainless steel pincers and analyzed the scratched area using XEDS. We conclude from the element mapping that the scratched area contains silicon. Therefore it is clear that in this case the layer of carbon (which we are referring to as a char in this paper) is deposited on the layer of silicon rather than on the Teflon surface.

Microscopic analyses of different fully and partially charred samples show that under the carbon layer there is a layer of silicon with some small amount of copper. The origin of the copper is probably the outer electrode, whereas silicon may come from the diffusion pump because the only difference in the facilities is the pump.

To eliminate this possible source of silicon, the MicroPPT was fired in a chamber with a turbopump (glass bell jar) for $2 \mathrm{~h}$ and at $1 \mathrm{~Hz}$. A typical image of the charred area in this case is shown in Fig. 4. One can see that the charring structure in this case is the same as that in Fig. 3a. It is interesting to note that in the microPPT sample fired in the turbopumped chamber (for a comparable amount of time), there is evidence of neither silicon nor any metal layer under the char.

An important observation from the microscopic analyses is the presence in most samples of a layer of metal under the char. In the cases where no metal layer is found under the char, the charred area has the same appearance. It is concluded that the char formation therefore may be the same in both cases. This fact may suggest that the carbon char is formed as a result of the carbon flux returned from the plasma. Another possible mechanism of char formation, incomplete Teflon decomposition, seems to be inconsistent with observations, that is, the presence of the metal and silicon layer between the Teflon surface and the char.

The microscopic structure of the charred areas is similar for different conditions under which the MicroPPT was fired. For instance, the effect of the discharge energy on the char microstructure is shown in Figs. 5 and 6. One can see that shapes and size characteristics are the same for two different energy levels. In both cases the carbon structures have a size of about several micrometers.

It should be noted that this conclusion about the origin of the carbon charring formation (due to the carbon flux returned from the plasma) could also be supported by qualitative comparison of the charring with the carbon structures developed during carbon deposition by DC electric arc discharge. ${ }^{15}$ The shape and size (about several micrometers) of the carbon microstructures are very similar in both cases. This comparison clearly indicates that similar microstructures develop during the carbon deposition and unstable growth of the carbon nanotubes. ${ }^{15}$

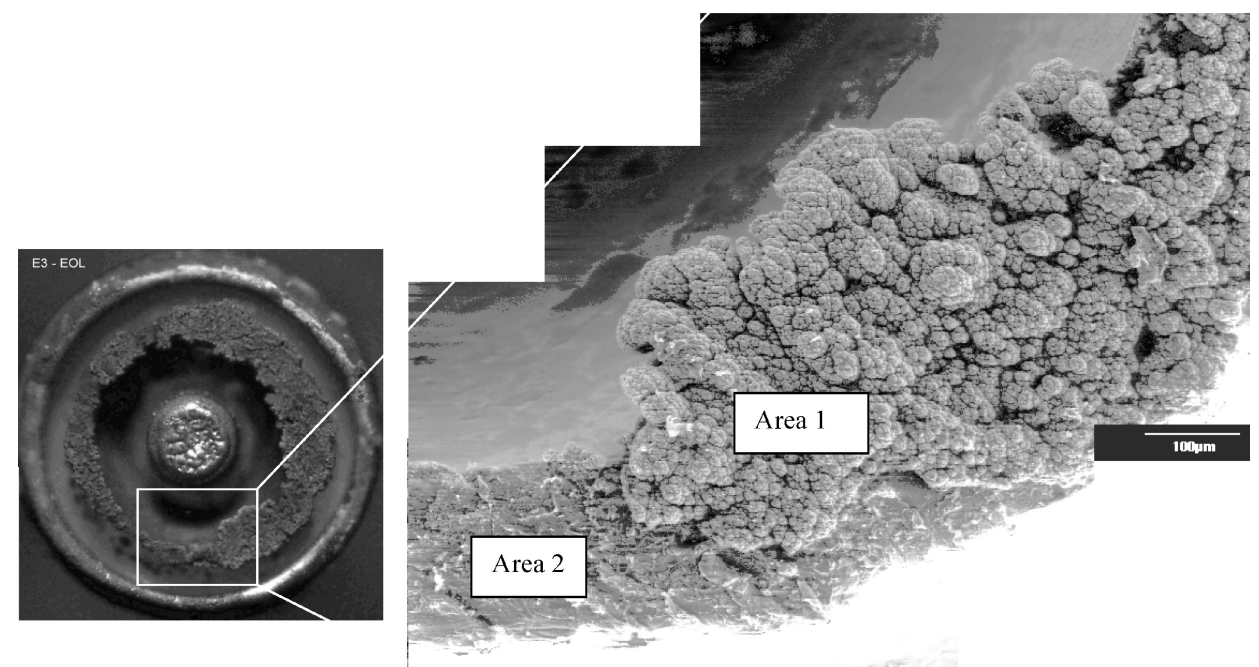

Fig. 2 Charred area on the propellant surface of the 3.6-mm micro-PPT. 

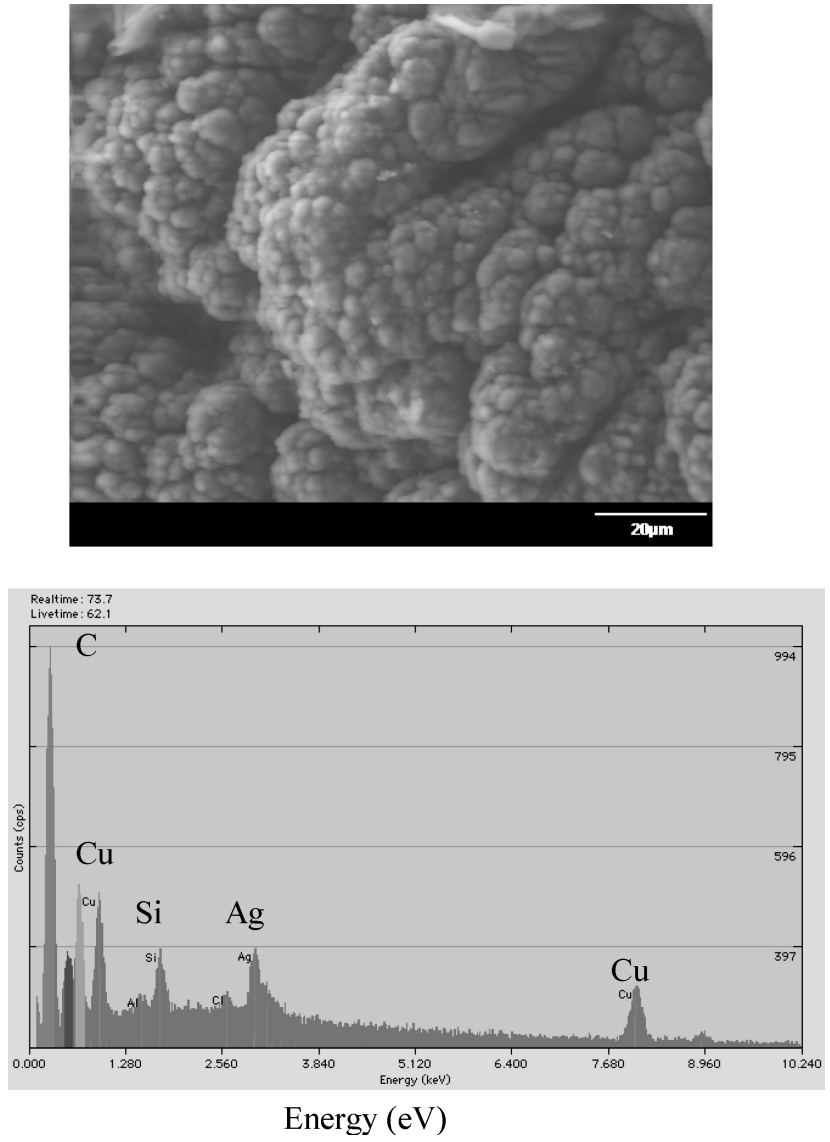

Fig. 3a Image and XEDS results for Area 1. The main peak corresponds to carbon.
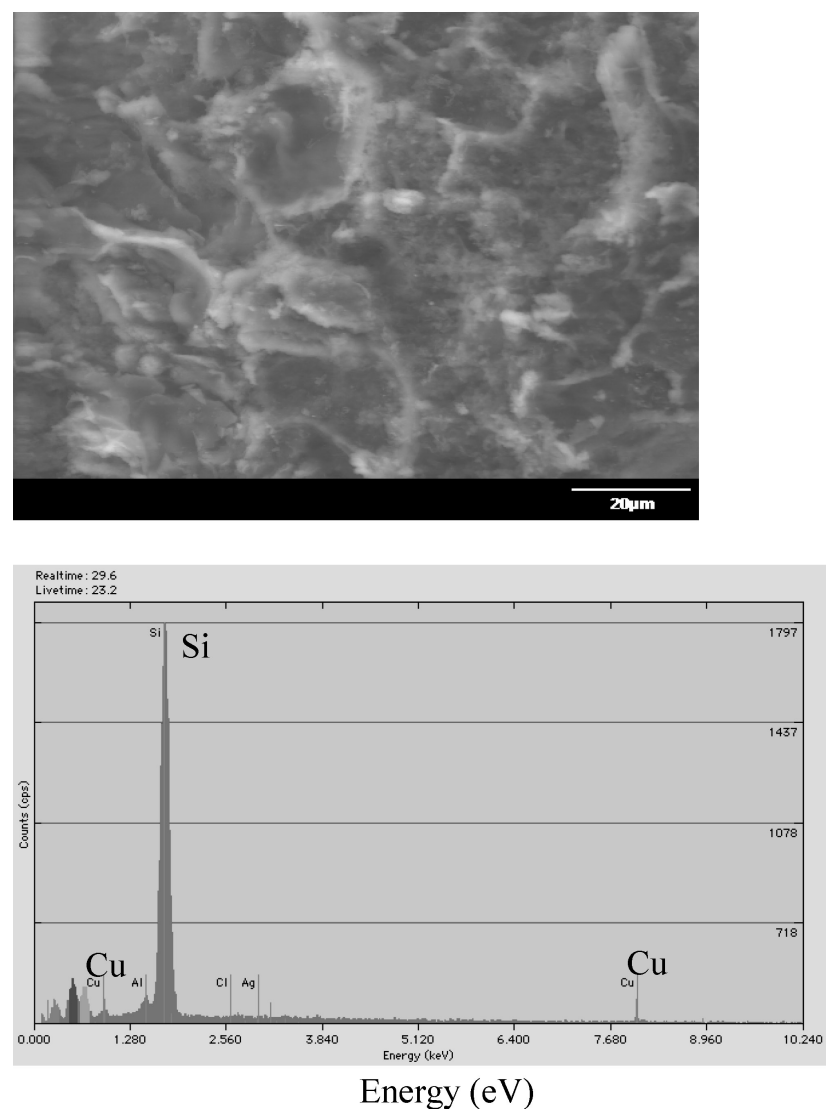

Fig. 3b Image and XEDS results for Area 2. The main peak corresponds to silicon.
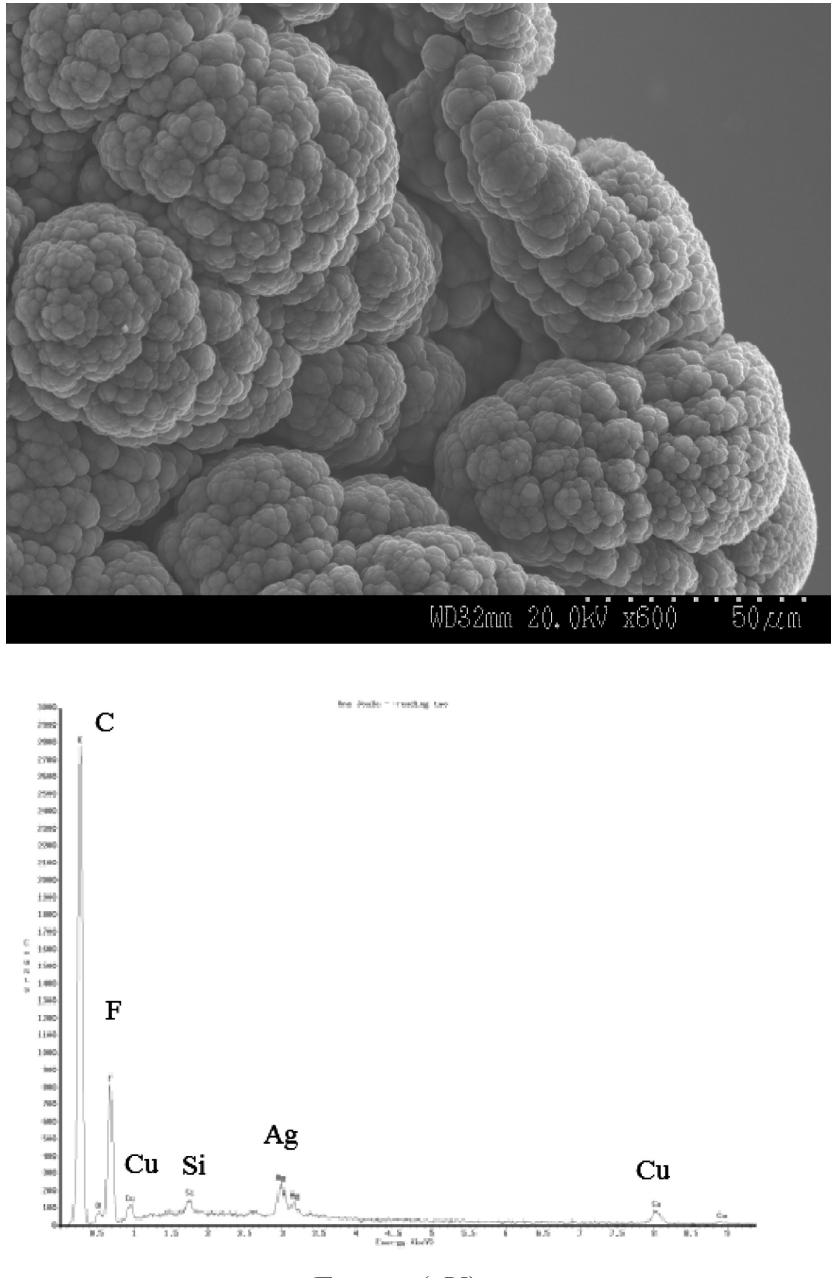

Energy (eV)

Fig. 4 Charred area image and XEDS results. The main peaks correspond to carbon and flourine.

\section{Model of the Plasma Layer Near the Ablated Surface}

In this section we describe a model of the plasma layer near the evaporating surface, with application to a micro-PPT that is shown schematically in Fig. 1. During the discharge, the plasma density near the propellant face is large (on the order of $10^{23}-10^{24} \mathrm{~m}^{-3}$, Refs. 16, 17) and therefore a fluid approach can be used. The plasmalayer model includes the following features: Teflon ablation, plasma energy balance, heat transfer from the plasma to the Teflon, current spreading in the near field, and an equivalent resistance-inductancecapacitance (RLC) electrical circuit model. Mechanisms of energy transfer from the plasma column to the wall of the Teflon include heat transfer by particle convection and by radiation. It is assumed that within the plasma layer all parameters vary in the radial direction $r$. The electron-energy-balance equation can be written in the form, ${ }^{16,17}$

$$
\frac{3}{2} n \frac{\mathrm{d} T_{e}}{\mathrm{~d} t}=Q_{J}-Q_{r}-Q_{F}
$$

The one-dimensional time-dependent model of the plasma layer is considered and Eq. (1) depends on the coordinate $r$ along the propellant face (see Fig. 1). The radiation heat flux $Q_{r}$ and particle-convection heat flux $Q_{F}$ depend on the plasma density and temperature. ${ }^{16,17}$ The one-dimensional time-dependent model of the plasma layer is considered and Eq. (1) depends on the coordinate $r$ along the propellant face (see Fig. 1). The radiation heat flux $Q_{r}$ and particle-convection heat flux $Q_{F}$ depend on the plasma density and temperature. ${ }^{16,17}$ According to Ref. 18, the radiation in continuum from a $\mathrm{C}+2 \mathrm{~F}$ plasma in the considered parameter range provides 


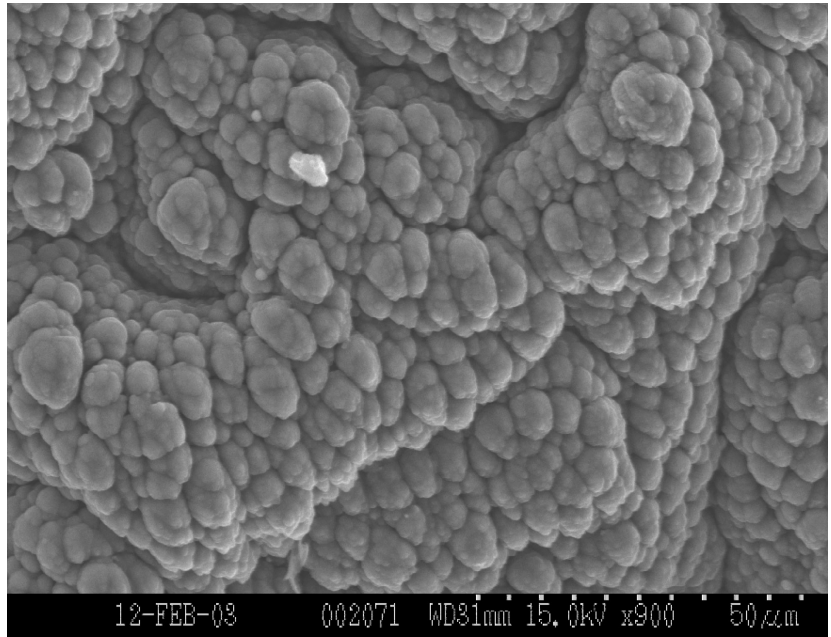

a)

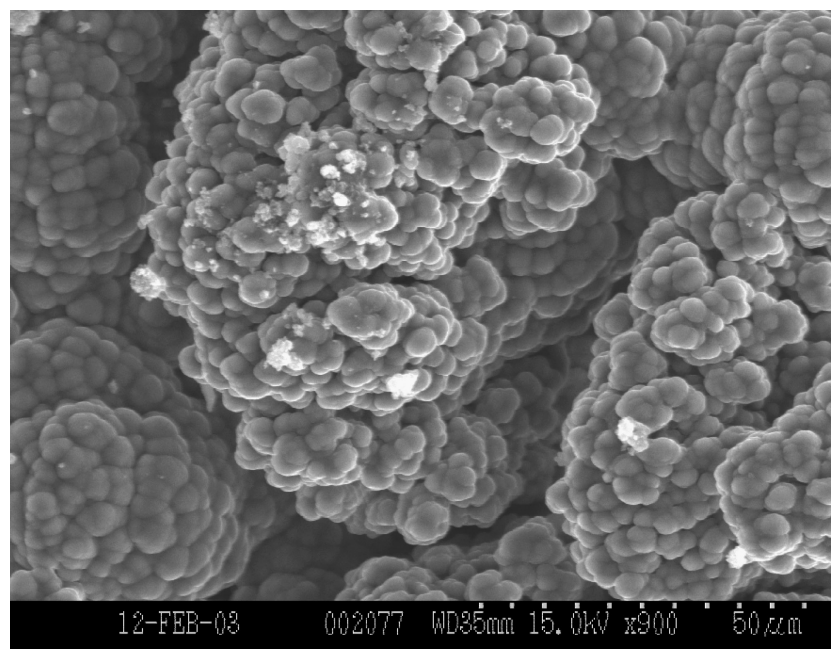

b)

Fig. 5 Charred area image. Effect of the discharge energy: a) $1 \mathrm{~J}$ and b) $3 \mathrm{~J}$.

the main contribution. The radiation energy flux $Q_{r}$ includes the radiation for a continuum spectrum based on a theoretical model. ${ }^{19,20}$ In the expression for $Q_{r}=A Z_{i}^{2} n^{e} T_{e}^{1 / 2}\left(1+\chi_{g}\right)$, the coefficient $A$ is a constant $\left(1.6 \times 10^{-38}\right.$ in SI units $)$ and $\chi_{g}=E_{g} / T_{e}$, with $E_{g}$ as the energy of the lowest excited state. The particle convection flux $Q_{F}$ includes energy associated with electron and ion fluxes to the Teflon and out of the plume, which lead to plasma cooling. The inputs for the model are thruster geometry, Teflon material properties, and Teflon equilibrium-pressure dependence on the surface temperature. More details about the model and computational methods can be found elsewhere. ${ }^{21}$

The Teflon surface temperature is calculated from the heattransfer equation with boundary conditions that take into account vaporization heat, surface radiation, and heat conductivity. Calculations show that surface radiation is negligibly small in the case considered. The solution of this equation is considered for limiting cases of substantial and small ablation rates very similar to those described in Refs. 16 and 17. The change of the Teflon surface properties due to char formation was not taken into account.

The Teflon ablation computation is based on a recently developed kinetic ablation model. ${ }^{22,23}$ In the transition region between the plasma and the ablated surface, two different layers are distinguished: (1) a kinetic nonequilibrium layer adjusted to the surface with a thickness of about one mean free path; and (2) a collisiondominated layer with thermal and ionization nonequilibrium. The solution for these two layers is coupled with the quasi-neutral plasma that allows the calculation of the ablation rate. The energy input in Eq. (1) depends upon the current density distribution near the ab-

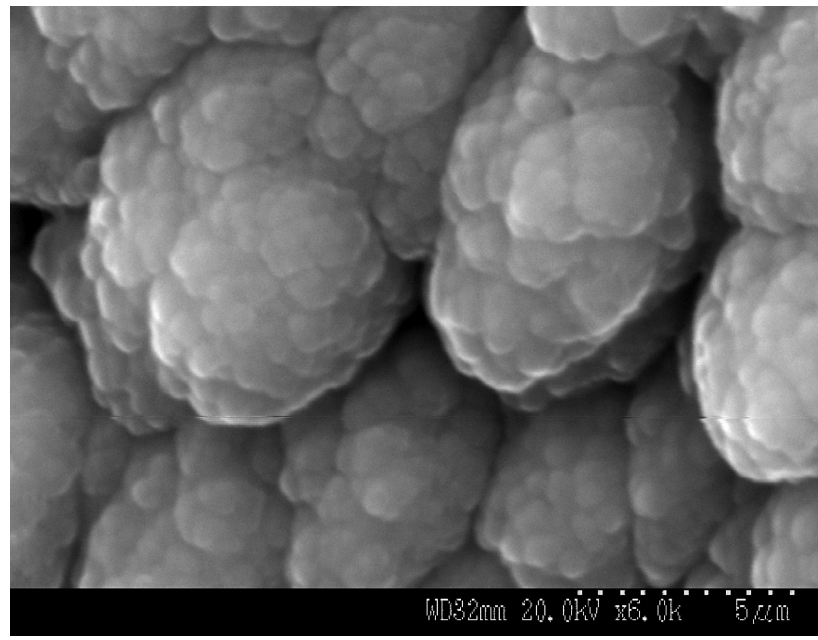

a)

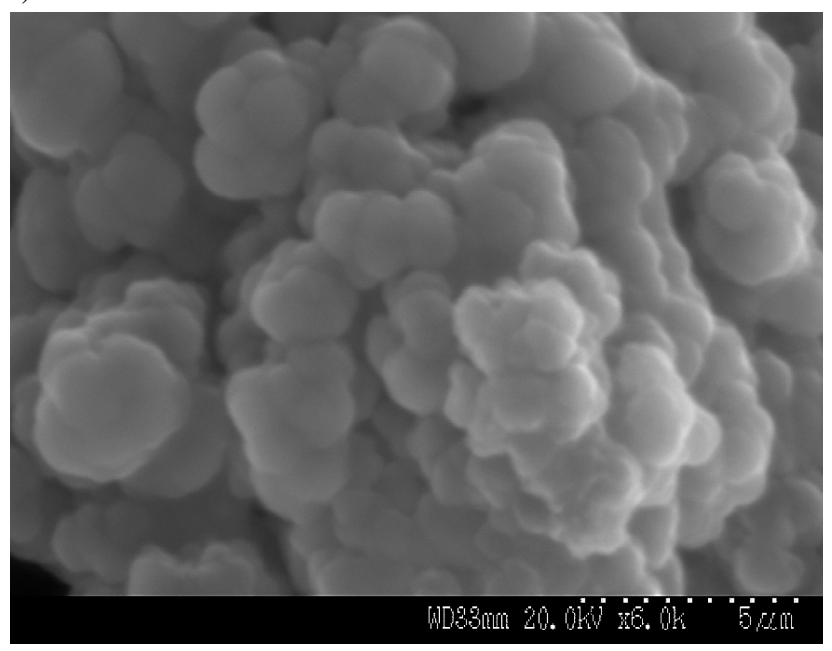

b)

Fig. 6 Charred area image (high magnification). Effect of the discharge energy: a) $1 \mathrm{~J}$ and b) $3 \mathrm{~J}$.

lated surface. In order to calculate the current density, the magnetic field distribution in the thruster near field is obtained. The magnetic field in the near-field plasma plume is calculated from the magnetic transport equation in the following form:

$$
\frac{\partial \boldsymbol{B}}{\partial t}=\frac{\nabla^{2} \boldsymbol{B}}{(\sigma \mu)}-\nabla \times\left(\frac{\boldsymbol{j} \times \boldsymbol{B}}{(e n)}\right)+\nabla \times(\boldsymbol{V} \times \boldsymbol{B})
$$

We assume that the magnetic field has only an azimuthal component and neglect the displacement current. Various terms on the righthand side of Eq. (2) may have importance in different regions of the plasma plume and therefore a general end-to-end plasma-plume analysis requires keeping all terms in the equation. In the case of the near plume of the micro-PPT, with a characteristic scale length of about $1 \mathrm{~cm}$, the magnetic Reynolds number $\operatorname{Re}_{m}=\mu \sigma L V \ll 1$ (where $V$ is the characteristic velocity $\sim 10^{4} \mathrm{~m} / \mathrm{s}$ ) and therefore the last term can be neglected. Our estimate also shows that the Hall parameter $\omega \tau \ll 1$ if the plasma density near the Teflon surface $n>10^{23} \mathrm{~m}^{-3}$. Therefore in the case considered the second term can also be neglected and Eq. (2) can be reduced to a magnetic diffusion equation having the following form:

$$
\frac{\partial \boldsymbol{B}}{\partial t}=\frac{1}{(\sigma \mu)} \nabla^{2} \boldsymbol{B}
$$

The current-density distribution was then calculated from the magnetic field distribution. This allows calculation of the Teflon temperature distribution from the energy input in Eq. (1). More details about the current and magnetic field distributions in the near field are presented in a parallel paper. ${ }^{21}$ 


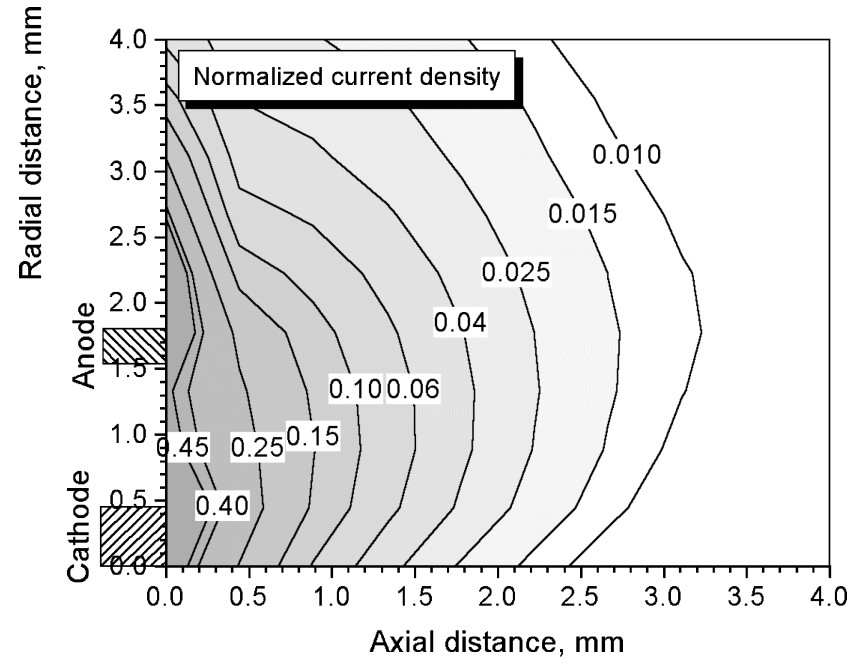

Fig. 7 Current-density distribution (normalized) in the near field of the 3.6-mm-diam micro-PPT. Electrode geometry is shown for reference.

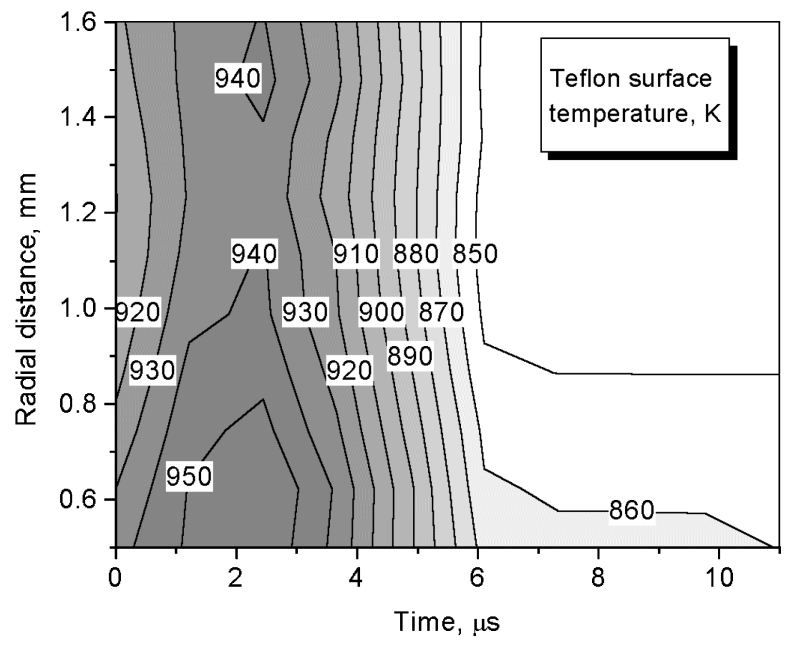

Fig. 8 Teflon surface-temperature $(K)$ temporal and radial (between electrodes) variation for micro-PPT design with diameter $3.6 \mathrm{~mm}$.

\section{Teflon Surface Temperature and Ablation Rate}

The calculated current density distribution near the Teflon surface in the $r-z$ plane is shown in Fig. 7. One can see that the current density has a minimum in the middle between electrodes due to the current spreading in the $r-z$ plane. According to the energy balance [Eq. (1)] and the heat-transfer equation at the Teflon surface, ${ }^{16,17}$ the surface temperature should depend on the current density. The spatial and temporal variation of the Teflon surface temperature is shown in Fig. 8. One can see that the Teflon surface temperature is nonuniform in the radial direction. It can be seen that in the 3.6-mmdiam thruster, the temperature has a minimum at radial distances of $1.1-1.3 \mathrm{~mm}$.

Because the Teflon ablation rate grows nonlinearly with the surface temperature, ${ }^{22,23}$ the model predicts a lower rate of ablation in the areas where the surface temperature has a minimum. By taking this into account, the effect of the temperature distribution may be related to the preferential charring of the Teflon surface observed experimentally, as shown in Fig. 9. It is interesting to note that comparison of the calculated temperature field and ablation rate with the photograph of the Teflon surface (Fig. 9) shows that the area with surface temperature and ablation rate minimum corresponds to the charred area in the case of the 3.6-mm-diam thruster.

\section{Effect of Discharge Energy}

In this section we investigate the effect of the discharge energy on ablation and char formation. In the model it is assumed that the

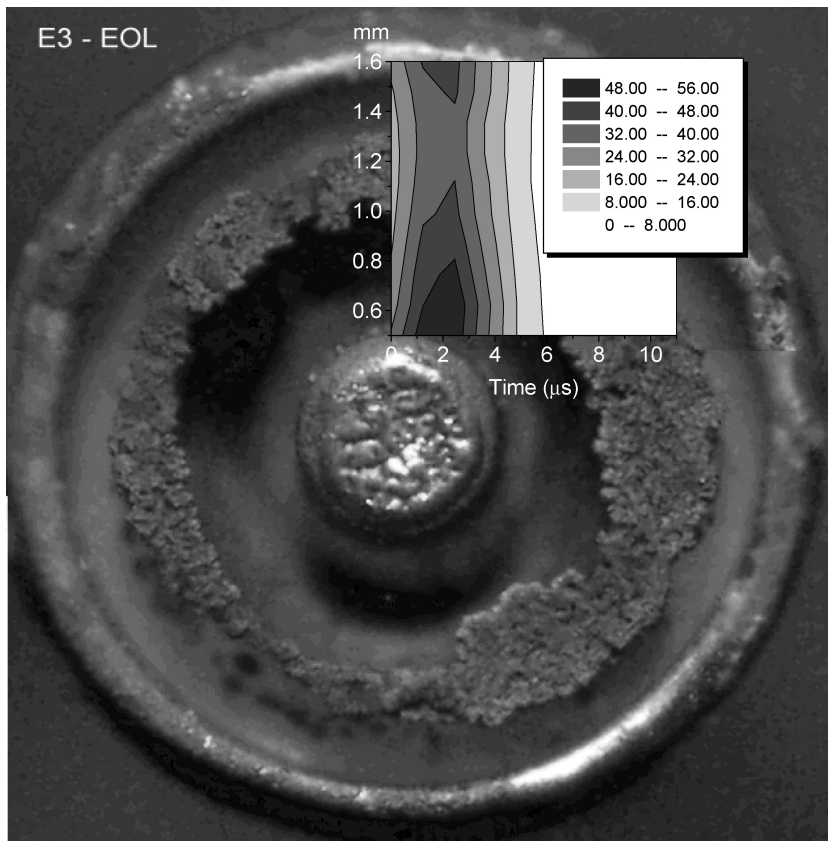

Fig. 9 Teflon surface photograph and the ablation rate $\left(\mathrm{kg} / \mathrm{m}^{2} \mathrm{~s}\right)$ in the case of a 3.6-mm-diam micro-PPT.

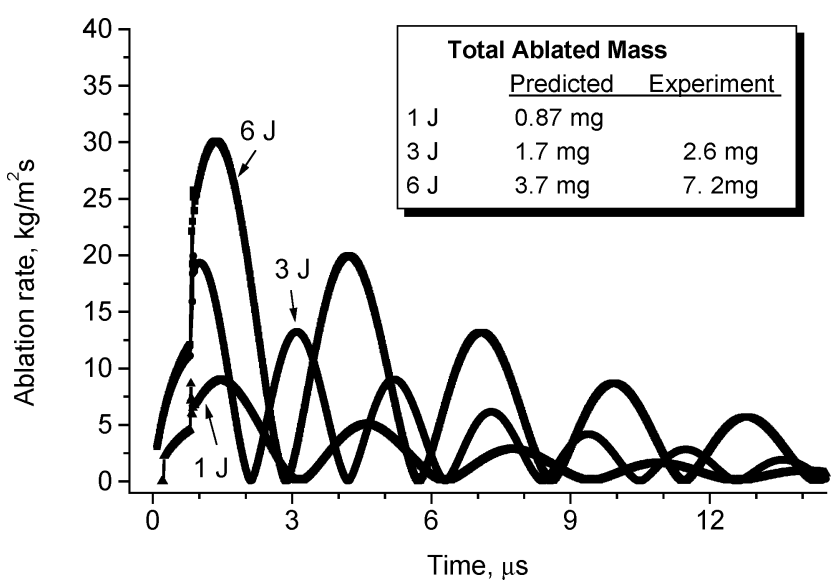

Fig. 10 Ablation rate temporal variation (in the midway between electrodes) for discharge energies of 1,3 , and $6 \mathrm{~J}$ for 6.3-mm-diam twoelectrode MicroPPT.

current is produced by an underdamped RLC circuit and has the form

$$
I(t)=I_{p} \sin (\alpha t) \cdot \exp (-\beta t)
$$

where $\alpha=\left(1 / L C-\beta^{2}\right), \beta=R / 2 L$, and $I_{p}=U_{o} /(L \alpha)$. From the comparison of $I(t)$ with the experimental current waveform in the case of $C=0.3 \mu \mathrm{F}$ it is estimated that $R=0.3 \Omega$ and $L=3.6 \times$ $10^{-7} \mathrm{H}$.

We consider the effect of the discharge energy $0.5\left(C U_{o}^{2}\right)$ on the Teflon surface temperature and the Teflon ablation rate. These results are shown in Fig. 10. One can see that with energy increase, the Teflon ablation rate increases as shown in Fig. 10. The total ablation rate is also shown and compared with measured value. It can be seen that generally good agreement is found. These results suggest that increasing the discharge energy for constant capacitance leads to enhanced Teflon ablation (and carbon char ablation) and therefore prevents char formation.

It was shown experimentally that the energy level affects the Teflon ablation. These experiments were conducted in a glass bell jar under a pressure of $10^{-6}$ torr. The char patterns for three different energies are shown in Fig. 11 after continuous firing for $2 \mathrm{~h}$ at $1 \mathrm{~Hz}$. There have been no experimental observations of cases where char 


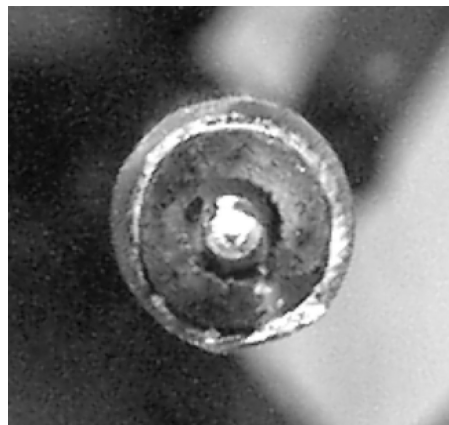

$1 \mathrm{~J}$

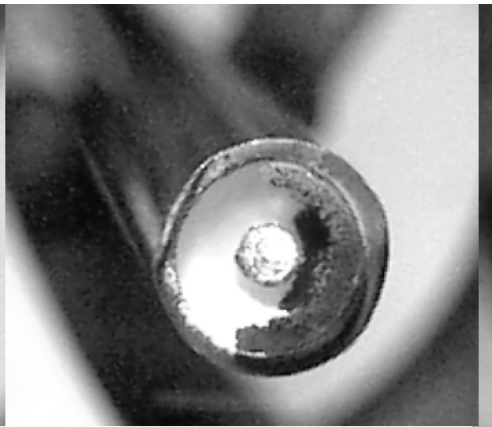

$3 \mathrm{~J}$

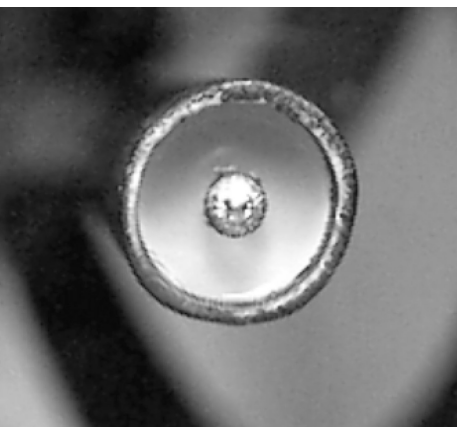

$6 \mathrm{~J}$

Fig. 11 Photograph of the micro-PPT propellant surface for discharge energies of 1, 3, and $6 \mathrm{~J}$ for 6.3-mm-diam two-electrode MicroPPT.

appeared, only to be cleaned up by subsequent discharges at the same energy. (Cleaning of the char formation by firing at higher discharge energies has been observed experimentally but is not considered within the context of this effort.) For these tests a $\frac{1}{4}$-in.-diam twoelectrode MicroPPT was energized using a $2.94-\mu \mathrm{F}$ capacitor. The charge voltage ranged from $823 \mathrm{~V}$ for the $1.0-\mathrm{J}$ case to $2016 \mathrm{~V}$ for the 6.0-J case. Clearly these voltages are insufficient to cause the surface breakdown needed for MicroPPT discharge initiation across a $\frac{1}{4}$-in.-diameter. Rather than complicate the test setup by using the three-electrode MicroPPT configuration, ${ }^{8,9}$ an auxiliary sparkplug, fired at $0.5 \mathrm{~J}$, was used to initiate the discharge on command. An auxiliary sparkplug effect on char formation was not observed.

One can see that in the case of small energy, charring is observed in the area between the electrodes, while in the case of large energy, there is no charring. The middle-energy case shows a level of char between the two extrema. This effect can be partially explained in terms of our model, which shows that higher discharge energy leads to higher Teflon surface temperature and higher ablation rate.

\section{Summary}

A microscopic analysis of the charred areas showed that they mainly contained carbon. In some cases, metal and silicon layers were found under the carbon char. The metal deposition originated from electrode erosion, whereas the silicon is assumed to come from the diffusion pump. In fact, when a turbopumping system was used, no silicon was obtained on the Teflon surface. In those cases where no metal layer was found under the char, the charred area had the same appearance. It is concluded that the char formation therefore may be the same in both cases, independent of the metal layer formed between the Teflon surface and the carbon char. In addition, particle simulation of the near-field plasma plume predicts a substantial population of ions having negative axial velocity up to about $10 \mathrm{~km} / \mathrm{s}$ (Refs. 12 and 21). This ion population creates backflow contamination that flows mainly onto the thruster itself. ${ }^{12,21}$ The carbon ions have a larger negative velocity due to their higher mobility, which results in their domination in the backflux to the thruster. More details about these simulations can be found in a parallel publication. ${ }^{21}$ Based on our observations and particle simulation it can be suggested that the carbon char is formed as a result of the carbon flux returned from the plasma rather than from incomplete decomposition of the Teflon.

A model of the plasma layer near the Teflon surface of a microPPT was developed that allows self-consistent calculation of the Teflon surface temperature and ablation rate. It was found that the propellant size had an important effect on the Teflon surface temperature distribution and the ablation rate. Generally we found that the Teflon surface temperature is nonuniform in the radial direction. For instance, in the 3.6-mm-diam thruster, the temperature has a minimum at radial distances of $1.1-1.3 \mathrm{~mm}$. The comparison of the temperature field and the ablation-rate distribution with a photograph of the Teflon surface shows that the area with surface temperature and ablation rate minima corresponded to the charred area in the case of the 3.6- $\mathrm{mm}$ thruster. This suggests that the char- ring may be related to the temperature effect. An analysis of the effect of the discharge energy $E$ on the temperature distribution showed that the Teflon surface temperature and the ablation rate can be increased by increasing $E$. At the same time, an increase in capacitance leads generally to a smaller ablation rate, though this effect can be considered to be marginal.

\section{Acknowledgments}

The first two authors gratefully acknowledge the partial financial support of the Air Force Office of Scientific Research through Grant F49620-02-1-0084. The AFRL authors were also partially supported through the Air Force Office of Scientific Research with Mitat Birkan as Program Manager. We also acknowledge John Mansfield, Chris Palenik, Joe Lohrum, and Frances N Skomurski from the University of Michigan for help with scanning electron microscopy analyses. The authors also acknowledge R. L. Burton (University of Illinois at Urbana-Champaign), I. I. Beilis (Tel Aviv University), and R. Aharonov (IonBond LLC) for valuable discussions.

\section{References}

${ }^{1}$ Burton, R. L., and Turchi, P. J., "Pulsed Plasma Thruster," Journal of Propulsion and Power, Vol. 14, No. 5, 1998, pp. 716-735.

${ }^{2}$ Vondra, R. J., and Thomassen, K. I., "Flight Qualified Pulsed Plasma Thruster for Satellite Control," Journal of Spacecraft and Rockets, Vol. 11, No. 9, 1974, pp. 613-617.

${ }^{3}$ Turchi, P. J., "Directions for Improving PPT Performance," Proceedings of the 25th International Electric Propulsion Conference, Vol. 1, The Electric Propulsion Society, Worthington, OH, 1998, pp. 251-258.

${ }^{4}$ Choueiri, E. Y., "System Optimization of Ablative Pulsed Plasma Thruster for Stationkeeping," Journal of Spacecraft and Rockets, Vol. 33, No. 1, 1996, pp. 96-100.

${ }^{5}$ Spores, R. A., Cohen, R. B., and Birkan, M., "The USAF Electric Propulsion Program," Proceedings of the 25th International Electric Propulsion Conference, Vol. 1, The Electric Propulsion Society, Worthington, $\mathrm{OH}$, 1998, 1997, p. 1

${ }^{6}$ Dunning, J. W., Benson, S., and Oleson, S., "NASA's Electric Propulsion Program," IEPC Paper 01-002, The Electric Propulsion Society, Worthington, OH, Oct. 2001.

${ }^{7}$ Zakrzwsky, C., Benson, S., Sanneman, P., and Hoskins, A., "On-Orbit Testing of the EO-1 Pulsed Plasma Thruster," AIAA Paper 2002-3973, July 2002.

${ }^{8}$ Spanjers, G. G., White, D., Schilling, J., Bushman, S., Lake, J., and Dulligan, M., "AFRL MicroPPT Development for the TEchSat21 Flight," IEPC Paper 2001-166, The Electric Propulsion Society, Worthington, OH, Oct. 2001.

${ }^{9}$ Spanjers, G. G., Bromaghim, D. R., Lake, C. J., Dulligan, M., White, D., Schilling, J. H., Bushman, S. S., Antonsen, E. L., Burton, R. L., Keidar, M., and Boyd, I. D., "AFRL Micro-PPT Development for Small Spacecraft Propulsion," AIAA Paper 2002-3974, July 2002.

${ }^{10}$ Boyd, I. D., Keidar, M., and McKeon, W., "Modeling of a Pulsed Plasma Thruster from Plasma Generation to Plume Far Field," Journal of Spacecraft and Rockets, Vol. 37, No. 3, 2000, pp. 399-407.

${ }^{11}$ Keidar, M., and Boyd, I. D., "Device and Plume Model of an Electrothermal Pulsed Plasma Thruster," AIAA Paper 2000-3430, July 2000.

${ }^{12}$ Keidar, M., and Boyd, I. D., "Electromagnetic Effects in the Near Field Plume Exhaust of a Pulsed Plasma Thruster," AIAA Paper 2001-3638, July 2001. 
${ }^{13}$ Gulczinski, F., Dulligan, M., Lake, J., and Spanjers, G. G., "Micropropulsion Research at AFRL," AIAA Paper 2000-3255, July 2000 .

${ }^{14}$ Antonsen, E., Burton, R., and Spanjers, G. G., "High Resolution Laser Diagnostics in Millimeter-Scale Micro Pulsed Plasma Thrusters," IEPC Paper 2001-157, The Electric Propulsion Society, Worthington, OH, Oct. 2001.

${ }^{15}$ Ajayan, P. M., Redlich, Ph., and Ruhle, M., "Balance of Graphite Deposition and Multi-Shell Carbon Nanotube Growth in the Carbon Arc Discharge," Journal of Materials Research, Vol. 12, No. 1, 1997, pp. 244-252.

${ }^{16}$ Keidar, M., Boyd, I. D., and Beilis, I. I., "Electrical Discharge in the Teflon CAvity of a Co-Axial Pulsed Plasma Thruster," IEEE Transactions on Plasma Science, Vol. 28, No. 2, 2000, pp. 376-385.

${ }^{17}$ Keidar, M., Boyd, I. D., and Beilis, I. I., "Model of an Electrothermal Pulsed Plasma Thruster," Journal of Propulsion and Power, Vol. 19, No. 3, 2003, pp. 424-430.

${ }^{18}$ Zemskov, A. I., Prut, V. V., and Khrabrov, V. A., "Pulsed Discharge in Dielectric Chamber,' Soviet Physics-Technical Physics, Vol. 17, 1972, pp. 285-289.

${ }^{19}$ Kozlov, G. I., Kuznetsov, V. A., and Masyukov, V. A., "Radiative Losses by Argon Plasma and the Emissive Model of a Continuous Optical Discharge," Soviet Physics-JETP, Vol. 39, No. 3, 1974, pp. 463-468.

${ }^{20}$ Raizer, Y. P., Gas Discharge Physics, Moscow, Nauka, 1987 [in Russian], p. 229.

${ }^{21}$ Keidar, M., Boyd, I. D., Antonsen, E. L., and Spanjers, G. G., "Electromagnetic Effects in the Near Field Plume Exhaust of a Micro-Pulsed Plasma Thruster," Journal of Propulsion and Power, Vol. 20, No. 4, 2004, pp. 961-969.

${ }^{22}$ Keidar, M., Fan, J., Boyd, I. D., and Beilis, I. I., "Vaporization of Heated Materials into Discharge Plasmas," Journal of Applied Physics, Vol. 89, No. 6, 2001, pp. 3095-3098.

${ }^{23}$ Keidar, M., Boyd, I. D., and Beilis, I. I., "On the Model of Teflon Ablation in an Ablation-Controlled Discharge," Journal of Physics D: Applied Physics, Vol. 34, June 2001, pp. 1675-1677.

\section{EFFECTIVE BISY MANACEMEN| \\ The best risk management book in the marketplace-comprehensive, easy-to-read, understandable, and loaded with tips that make it a must for everyone's bookshelf.- Harold Kerzner, PhD, President, Project Management Associates, Inc. EFFECTIVE RISK MANAGEMENT: SOME KEYS TO SUCCESS, SECOND EDITION Edmund H. Conrow}

$\mathbf{T}$ he text describes practices that can be used by both project management and technical practitioners including those who are unfamiliar with risk management. The reader will learn to perform risk planning, identify and analyze risks, develop and implement risk handling plans, and monitor progress in reducing risks to an acceptable level. The book will help the reader to develop and implement a suitable risk management process and to evaluate an existing risk management process, identify shortfalls, and develop and implement needed enhancements.

The second edition presents more than 700 risk management tips to succeed and traps to avoid, including numerous lessons derived from work performed on Air Force, Army, Navy, DoD, NASA, commercial, and other programs that feature hardware-intensive and software-intensive projects.

\section{Contents:}

Preface - Introduction and Need for Risk Management • Risk Management Overview • Risk Management Implementation - Risk Planning • Risk Identification • Risk Analysis • Risk Handling • Risk Monitoring • Appendices

2003, 554 pages, Hardback

ISBN: 1-56347-581-2

List Price: $\$ 84.95$

AIAA Member Price: $\$ 59.95$

Publications Customer Service, P.O. Box 960

Herndon, VA 20172-0960

Phone: 800/682-2422; 703/661-1595

Fax: 703/661-1501

E-mail: warehouse@aiaa.org•Web: www.aiaa.org 